\title{
ALGUMAS QUESTÕES SOBRE SEXUALIDADE E GÊNERO NAS LEIS DOS \\ ESTRATOS SACERDOTAIS DO PENTATEUCO: \\ OS CASOS DE Lv 20, 20-21 E DE Nm 5, 11-31
}

Autora: Clarisse Ferreira da Silva*

\section{Resumo}

As leis bíblicas oriundas dos grupos sacerdotais podem ser reconhecidas por sua atenção mais especificamente voltada aos ritos e ao santuário, sempre em conformidade com aquilo que estes grupos consideravam condizente com a santidade de $\mathrm{YHWH}^{1}$, o Deus de Israel. Mas não apenas isso, em alguns estratos, elas demonstrariam preocupação especial em relação à santidade do povo que adorava YHWH, bem como à da terra em que seu Templo se erguia. Os ideais sacerdotais expressavam-se também através de leis que visavam regular o corpo humano e o modo como as pessoas deviam viver sua sexualidade a fim de que refletissem, irrestritamente, tal modelo de santidade.

Palavras-chave: Torá, Fontes Sacerdotais (=P e H), Livro de Levítico, Livro de Números, Sexualidade.

\begin{abstract}
The biblical laws derived from priestly strata can be recognized by their attention specifically focused on the rites and the sanctuary, always in accordance with what priestly groups considered in consistence with the holiness of YHWH, the God of Israel. Not only that, but in some strata they demonstrated special concern in relation to the holiness of the people who worshipped YHWH, as well as to the land where the Temple was built. The priestly ideals were also expressed through laws which aimed at regulating the human body and how people should live their sexuality in a way that it would reflect, without restriction, such model of sanctity.
\end{abstract}

Keywords: Torah, Priestly Sources $(=\mathrm{P}$ and H), Book of Leviticus, Book of Numbers, Sexuality.

\footnotetext{
* A autora é doutorada pelo Programa de História Social da FFLCH/USP e pesquisadora do Centro de Estudos Judaicos da mesma universidade.

${ }^{1}$ As letras latinas, Y, H, W, H, correspondem, aproximadamente, às letras hebraicas Yod, Hei, Waw, Hei, que formam o tetragrama, o nome do Deus de Israel. Hoje o tetragrama é impronunciável, não somente por motivos religiosos relacionados ao mandamento que proíbe pronunciar o nome de Deus em vão, mas também porque sua vocalização perdeu-se com o tempo (lembrando que o alfabeto hebraico antigo é consonantal, ou seja, sem símbolos gráficos para as vogais).
} 
No presente estudo, propomo-nos a fazer uma tradução comentada e analisar dois trechos legais da "Torá",2 que tratam de tabus sexuais dentro da sociedade israelita: Lv 20, 2021 e Nm 5, 11-31. Todos os indícios textuais, estilísticos e ideológicos levam à conclusão de que estamos aqui diante de textos provenientes das fontes sacerdotais do Pentateuco ${ }^{3}$. Iniciamos com duas leis de Lv 20, 20-21 que proíbem, respectivamente, a relação sexual com a tia e com a cunhada. ${ }^{4}$

1) Levítico 20, 20-21

\section{O texto de Lv 20-21 foi por traduzido como segue:}

20) E o homem que se deitar com sua tia, descobriu a nudez de seu tio; carregarão a sua falta, sem descendência morrerão. ${ }^{5}$

21) E o homem que tomar a mulher de seu irmão, é uma abominação impura ${ }^{6}$; descobriu a nudez de seu irmão, ficarão sem descendência. ${ }^{7}$

2 A Torá perfaz os cinco primeiros livros da Bíblia (Gênesis, Êxodo, Levítico, Números e Deuteronômio), atribuídos a Moisés, cujo conjunto é conhecido, pelos cristãos, por seu nome grego, Pentateuco.

${ }^{3}$ As fontes que perfazem a Torá são, de modo geral, divididas em "J" (javista, advinda da corte de Judá, o reino do Sul, cuja capital era Jerusalém); "E" (eloísta, advinda dos círculos proféticos de Israel, o reino do Norte, cuja capital era Samaria); "D" (deutoronomista, cujo núcleo pode ter se originado no Norte, mas foi desenvolvido provavelmente pela elite agrária e profissionais de justiça de Jerusalém após a queda do reino de Israel diante da Assíria em 722 a.C.) e, finalmente, "P", (do inglês "Priest" ou do alemão "Priester") e H (do inglês, "Holiness"; P e H são as duas fontes sacerdotais oriundas do santuário central de Jerusalém). Atualmente, essa divisão clássica, divulgada especialmente por Wellhausen, é contestada por vários especialistas, mas muitos outros ainda a consideram, em sua base, a melhor explicação para a complexa composição do Pentateuco.

${ }^{4}$ Cf. também Lv 18. Ambos os capítulos fornecem uma lista de relações sexuais proibidas, como incesto etc.

5 "ערירים ימתו". Outra tradução de "עריר". ("ariri, que traduzimos por "sem descendência"), sugerida por Suzana Chwarts, é "infecundo". Ainda outra opção de tradução seria: "morrerão sem filhos" (as bíblias consultadas - Bíblia de Jerusalém, Bíblia Ave-Maria e TEB - são unânimes nessa escolha; Friedman: childless). Chwarts ainda expande esses sentidos ao explicar: "O sentido de 'ariri como estéril, sem filho, é confirmado pelo uso do termo em Lv 20: 20, 21, que incorpora também, segundo a minha análise desses textos, o sentido de exclusão e desenraizamento.”. Em nota, a autora acrescenta: "O significado de 'ariri é explicado por Abraão em Gn 15:3: D' não lhe deu zera' (sêmen, semente). O significado de zera 'é, por sua vez, explicado por D' no versículo seguinte: 'aquele que sairá de tuas entranhas' (Gn 15,4). Aqui o filho é aquele que sai do corpo do pai ... em contraste com aquele que é membro, filho e servo da casa. ... O fator que determina essa distinção é... a esposa legal, aquela cuja fertilidade provém de uma bênção especial - com sentido corporativo - por parte da divindade "eu a abençoarei, ela se tornará nações, e dela sairão reis de povos (Gn 17: 16).” (CHWARTS, 2004, p. 77, Nota 86).

${ }^{6}$ O termo "נדה" (niddah) significa literalmente "menstruação". Porém, como figura de linguagem para descrever atos ou elementos impuros na esfera ritual ou moral, o termo foi encontrado traduzido tanto por "impureza" como por "abominação". Cf. etimologia de niddah em CHWARTS, p. 139, Nota 26.

7 "ערירים יהיו". Outras propostas de tradução apresentadas são: "infecundos viverão" (Suzana Chwarts), "serão privados de filhos" (TEB), "não terão filhos" (B.Av.), "they will be childless" (Friedman). A Bíblia de Jerusalém mantém a mesma tradução do v. 20. 
O presente trecho pertence a um contexto maior de chamamento de Israel a ser um povo santo "assim como YHWH é santo" (cf. Lv 20, 7-8.26). A grande função sacerdotal, isto é, distinguir (grifo da autora) entre o puro e o impuro e entre o santo e o profano, é o tema entre os versículos 24-26. O chamado para ser santo faz parte de um programa nacional pretendido pelos sacerdotes que escreveram esse complexo de Leis, cuja meta era converter Israel em uma nação santificada de modo que YHWH, seu Deus, que habitava no meio seu povo no Templo de Jerusalém, pudesse ali permanecer e abençoá-los ${ }^{8}$. No v. 26, é Deus quem distingue esse povo entre os demais para cumprir este destino: "E sereis para mim santos porque Eu, YHWH, sou santo e vos distingui dentre os povos para serdes meus." (grifo da autora).

Os crimes sexuais listados no cap. 20 de Lv são basicamente classificados em dois tipos: aqueles punidos pela pena capital (vv. 10-16) e aqueles passíveis da pena de Karet ("corte"; vv. 17-21). Segundo Baruch Schwartz, a natureza da ameaça "כרת" (Karet), "ser cortado" do "povo", de "Israel" ou, ainda, de "seus povos", é de esfera divina e nunca da alçada humana, quer por um tipo de "excomunhão" ou por pena capital. Literalmente, a raiz da palavra refere-se, p. ex., à amputação de um membro do corpo ou ao corte de uma árvore do meio de uma floresta. A metáfora aponta, então, para a extinção da pessoa ou de sua descendência da sociedade (dando fim a seu nome, tragédia pessoal e familiar no mundo antigo), ainda durante a sua existência (ou de seus descendentes), "impedindo sua continuidade". Sempre é Deus quem a pronuncia, indicando o resultado propriamente dito ou ainda ser Ele mesmo o executor da sentença. O legislador nunca estabelece como a sentença será efetuada, pois cabia somente a Deus decidir individualmente a pena: esterilidade, morte prematura, morte misteriosa, praga, morte da descendência (v., p. ex., a história dos filhos de Eli em $1 \mathrm{Sm} 2$ a 4). Karet baseia-se assim na crença de que Deus fará justiça, mesmo que não seja durante a vida do culpado. A única certeza é sobre o resultado: Deus o destruirá, não se sabe o momento. O transgressor, contudo, deve conviver com a consciência de sua pena e de seu fim, no futuro próximo ou um pouco mais distante, através do fim de sua posteridade ${ }^{9}$. Patai afirma: “... (Lev 20: 20) is a penalty almost as severe as being actually put to death; it is deferred death sentence." ${ }^{10}$ Observa-se, assim, que o sentido pretendido pelo texto de Levítico

\footnotetext{
${ }^{8}$ Segundo o pensamento sacerdotal, a impureza acumulada pelas transgressões do povo - que oficialmente deviam ser expiadas (=limpas) através de rituais sacrificais, embora nem sempre alcançassem esse objetivo por motivos variados - tinham a capacidade de fazer Deus abandonar Sua morada. A premissa é que um Deus santo não poderia viver contínua e indefinidamente em meio à impureza.

${ }^{9}$ Cf. sobre Karet em SCHWARTZ, 1999, p. 52-7.

${ }^{10}$ PATAI, 1959, p. 82. Também podemos lembrar aqui da matriarca Raquel em Gn 30, 1, que, em seu desespero, preferia a morte a não gerar filhos para seu marido.
} 
não seria exclusiva ou unicamente o de que os envolvidos passariam a ser incapazes de gerar, mas sim de que eles mesmos e seus descendentes, em algum momento, seriam destruídos e/ou não mais contados como filhos de Israel, ou seja, não gerariam zera' (cf. na Nota 5, o significado teológico do termo). Já para Chwarts, tratar-se-ia da falta de reconhecimento social da descendência dessas uniões ilícitas:

Em outras palavras, se essa união ilícita produzir fruto, apesar de este ser biologicamente filho de seu pai, ele não será considerado legítimo descendente - zera - e não servirá para perpetuar a linhagem patrilinear. Dessa forma, seus progenitores serão cortados da linhagem de Israel; não "terão um nome em Israel”, nem “construirão a Casa de Israel.

O código sacerdotal, de qualquer modo, buscaria, por meio de tais leis, cumprir sua função de distinguir o puro do impuro e de santificar um "povo para YHWH”. Isso acontecia ao excluir-se socialmente o transgressor pela ausência de uma descendência no meio de Israel.

Eilberg-Schwartz faz notar que o corpo humano, na Bíblia, ganha uma conotação simbólica e um significado religioso. A santidade, enfim, começa pelo corpo, responsabilidade primeira que Deus conferiu ao homem. A pertença e consagração total a YHWH é também física. O autor explica: "In ancient Judaism, cultural conflicts of this sort developed around the human body, generating an intense preoccupation with the body and its processes. Ancient Jews multiplied rules that both regulated the body and turned the body into a symbol of other significant religious concerns." ". Os versículos estudados são exemplo desse fenômeno religioso israelita (de modo especial, sacerdotal). Somando-se à preocupação com o corpo, percebe-se também seu forte enfoque em questões de sexualidade ${ }^{12}$ e nos processos fisiológicos naturais, como a menstruação ou a ejaculação. $\mathrm{Na}$ perspectiva sacerdotal, contudo, tais processos são fonte de impureza ritual ${ }^{13}$. As leis e narrativas que abordam o tema quase invariavelmente são classificadas como fonte $\mathrm{P}$ ou $\mathrm{H}$ (=sacerdotal), em especial no livro de Levítico. Ao entrar no mérito de que impureza ritual não equivaleria a pecado (no sentido de um ato iníquo que alienaria a pessoa de Deus ${ }^{14}$ ), o autor cita

\footnotetext{
${ }^{11}$ EILBERG-SCHWARTZ, 1999, p. 55

${ }^{12}$ Bird compara as narrativas de criação das fontes J e P (Gn 2-3 e Gn 1, respectivamente) e percebe diferenças fundamentais em sua visão da sexualidade e do relacionamento homem-mulher: "In J's view the sexual act that unites man and woman is the sign of an intended and original union. The man and the woman do not simply exist along-side one another, as partners in work - though they are that; nor is their sexuality created primarily for procriation (as in P)." (BIRD, 1997, p. 47, Nota 89).

${ }^{13}$ Lv 12, 15. A preocupação com a ingestão de alimentos impuros (Lv 11), doenças de pele (Lv 13-14) ou desfiguração do corpo (Lv 21, 16-23) revelam a vontade de poder controlar as fronteiras e limites entre o corpo e seu exterior, em busca da integridade física que também significa santidade.

${ }^{14} \mathrm{O}$ capítulo 20 é considerado por muitos especialistas parte de uma fonte sacerdotal posterior à fonte $\mathrm{P}$, a denominada fonte $\mathrm{H}$ (do termo Holiness, como vimos na Nota 3 acima). Os autores de $\mathrm{H}$, sim, teriam expandido a noção de impureza para além da esfera da impureza ritual física, que é essencialmente desassociada da ofensa moral. Cf. nosso debate sobre o assunto em SILVA, 2013, p. 120 ss.
} 
exatamente o capítulo 20 de Lv, cujo tema é a sexualidade (em suas relações ilícitas, segundo esse código legal), como uma possível exceção à regra, pois, em suas palavras, "it does constitute an offense against God" $" 15$. Na opinião do autor, foi através dos escritos sacerdotais que esse esforço de governo do corpo entrou primeiramente no Judaísmo, sendo, posteriormente, parte importante da elaboração rabínica e de Qumran. Para o autor, não fosse o livro do Levítico, o fenômeno da proeminência e centralidade das questões do corpo (ou da sexualidade), dentro do Judaísmo, não teriam tido lugar ${ }^{16}$.

Citando a explicação clássica de Mary Douglas ${ }^{17}$ no que se refere à preocupação social e nacional judaicas por sua própria fronteira política acabar por refletir-se na preocupação microcósmica pelo limite do corpo, Eilberg-Schwartz, porém, questiona-se por que tal preocupação teria sido veiculada mais especificamente pelo grupo sacerdotal ${ }^{18}$. O autor aponta então para dois elementos de certa forma conflitantes no que toca à doutrina sacerdotal e que constituiriam o cerne da ambiguidade com relação ao corpo nas Escrituras: a ordem divina de crescer e multiplicar $(\mathrm{Gn} 1,28)$ e a afirmação, na narrativa da criação, de que o homem e a mulher seriam a imagem de Deus $(\mathrm{Gn} 1,26-7)^{19}$. Nas palavras do autor: "There

\footnotetext{
${ }^{15}$ Em nota, Bird explica: "Israel's view of the proper place of sex and the harsh penalties laid upon sexual offenders presumably reflect a deliberate antithesis to the practices of the surrounding peoples (specifically Canaanites), but they may also be rooted in Israel's peculiar understanding of herself as a 'holy people'." (BIRD, 1997, p. 78, Nota 11).

${ }^{16}$ EILBERT-SCHWARTZ, 1999, p. 55-6.

${ }^{17}$ Ver, p. ex., DOUGLAS, 1999.

${ }^{18}$ A teoria de Douglas, para o autor, seria falha por não ter percebido esse aspecto. Se o problema fosse a pressão externa, a preocupação com o corpo não estaria tão restrita e centralizada no Lv e nos escritos sacerdotais.

${ }^{19}$ Como homem e mulher, que precisam ter relações para procriarem-se, poderiam ser a imagem de um Deus monoteísta, sem parceira (Ele é descrito como homem - pai, guerreiro, rei e como esposo de Israel - ou designado pelo gênero masculino - apesar de às vezes ser descrito metaforicamente com características ou em funções femininas) e incorpóreo (é bom lembrar também da proibição de qualquer representação da divindade, que, para o autor, deve-se ao dilema da sexualidade do Deus único; cf. EILBERT-SCHWARTZ, p. 65)? Eilberg-Schwartz explica: "It is 'generic Man' that is the image of God, but not humankind as sexually differentiated" (Op. Cit., p. 62). Para o autor, a passagem bíblica da "imagem de Deus" foi elaborada de forma obscura, intencionando exatamente camuflar tais problemas (Op. Cit., p. 66). E comenta: "If these religious convictions had gained the upper-hand, they might have generated either a renunciation of the body in general or sexuality in particular. But these impulses in Israelite religion came in conflict with the priests' equally strong commitment to the importance of human sexuality as the vehicle for reproduction." (Op. Cit.; cf. também p. 64-5). Temos outro exemplo com o profeta Ezequiel, também ele sacerdote, em sua visão da carruagem divina, guiada pelos querubins, que descreve a forma de seus corpos como "humana" (esses querubins, no entanto, possuíam quatro rostos: um humano e, os outros três, de animais), i.e., eles fixavam-se "eretos". É possível que tivessem apenas uma perna cada (cf. em Ez 1, 7 o uso do singular quando o profeta descreve as "pernas" das criaturas; v. GREENBERG, p. 44). Isso leva a pensar-se na possibilidade de que os querubins fossem assexuados. É um problema que Ezequiel tenta evitar quando descreve a figura divina, uma figura semelhante ao homem e que "a partir do que parecia ser sua cintura para baixo, vi como uma aparência de fogo, e uma luz resplandecente ao seu redor." (Ez 1, 27; trad. da autora). Podemos lembrar, outrossim, da comunidade sacerdotal de Qumran, que, em um contexto particular de espera escatológica, parece ter, pelo menos em um primeiro
} 
was no escape for the body. Pressed between these conflicting impulses, the body became an object of cultural elaboration."20. A preocupação com o corpo parece passar por outra questão central para a base sacerdotal e sua tradição: a procriação - uma bênção divina primordial - e sua consequência natural, a descendência (legítima e pura), e especialmente, a descendência patrilinear. A circuncisão seria mais um símbolo dessa linhagem construída por homens, sendo uma ligação simbólica entre "masculinidade, genealogia e reprodução." ${ }^{21}$ A sucessão legítima na função litúrgica e cultual, por exemplo, era transmitida exclusivamente através da linhagem masculina de Levi, e, no ministério sacerdotal, através de Aarão, e sumo sacerdotal, através de Zadoc. Eilberg-Schwartz resume:

The priesthood, therefore, legitimated itself with a kinship idiom. This idiom shaped the larger interests of the priestly community and accounts for the obsessive interest in detailing genealogies. ... Since lineages are replenished by the reproduction of its members, societies that define themselves through a kinship idiom frequently focus intense interest on human fecundity and clear lines of descent. ${ }^{22}$

Nessas leis de cunho sexual, portanto, vemos a tentativa de salvaguardar tanto a pureza sacerdotal quanto a do povo, projeto nacional de seus legisladores. O "idioma" sacerdotal também, como vimos, fala a linguagem da distinção e classificação. Assim, segundo EilberSchwartz, segundo a doutrina de $\mathrm{P}$ da criação, os israelitas teriam duas responsabilidades: manter a ordem cósmica (por meio do ritual) bem como a classificação das coisas criadas por Deus, sem misturá-las (p. ex., por meio das leis dietéticas - Kashrut - e pelas leis de moral sexual como as que vemos em Lv ${ }^{23}$. E, para isso, os israelitas deviam frutificar e multiplicarse a fim de levar adiante o projeto divino de criação ordenada e de garantir as diversas linhagens sociais dentro de Israel. Entretanto, ainda segundo o autor, a sexualidade em si, para o pensamento sacerdotal, seria em princípio boa apenas porque Deus assim o disse e abençoou. Ao mesmo tempo, porém, configurar-se-ia um símbolo da diferença entre a humanidade e seu Criador. O fato é que, na prática, a relação sexual contaminava e era fonte de impureza ritual, afastando o homem do sagrado, mesmo que temporariamente. Nas palavras de Eilberg-Schwartz, "While the priests regard reproduction one of the most important religious injunctions, semen is contaminating, even if ejaculated during a legitimate act of intercourse (Lev. 15: 16-18).... In the very act of carrying out God's will, one alienates

momento (ou mesmo em toda a sua história) ou talvez entre seus grupos internos mais radicais, renegado sua sexualidade.

${ }^{20}$ EILBERT-SCHWARTZ, 1999, p. 56.

${ }^{21}$ Op. Cit, p. 57-8. Ao contrário, segundo Eilbert-Schwartz, o potencial reprodutivo e processos naturais femininos de reprodução, menstruação e parto, são símbolos ligados à morte (Op. Cit., p. 58), estado de impureza por excelência.

${ }^{22}$ Op. Cit., p. 59.

${ }^{23}$ EILBERT-SCHWARTZ, 1999, p. 61. 
oneself from God by becoming contaminated."24. Se relações legítimas podiam trazer contaminações individuais, relações ilícitas, consideradas crimes de alta gravidade, traziam a contaminação social, colocando em perigo a linhagem e fazendo "a terra pecar". Relações ilícitas, como as que vimos nos dois versículos estudados, são punidas ao excluírem-se os envolvidos do meio do povo, "cortando-se" sua descendência do grupo ou mesmo por sua morte. Segundo Eilberg-Schwartz,

these tensions help explain the obsessive interest in the human body in priestly culture. The elaboration of the rules around the body was in part an attempt to control a puzzling object. But these rules did more than control a 'foreign body'. The absorption in legal regulations also diverted attention from the fundamental conflicts that surrounded the body. Absorbed by the legal particularities surrounding ejaculation, menstruation, and skin disease, those inside and outside the priestly community would have lost sight of the larger dilemmas that inhered in the priests' religious culture. It is for this reason too that the body became one of the richest sources of symbols in the priestly community. ${ }^{25}$

\section{2) Números 5, 11-31}

A conhecida perícope da mulher suspeita de adultério (=Sotah) foi traduzida como segue:

11) Falou YHWH a Moisés dizendo:

12) Fala aos filhos de Israel e dize-lhes: se houver um homem, um homem cuja mulher desviar-se e lhe for infiel

13) tendo um homem deitado com ela e tido relações sexuais ${ }^{26}$ e, se isso tiver ocorrido escondido $^{27}$ dos olhos de seu marido e ela tenha mantido segredo e tendo ela se tornado impura sem testemunha contra ela e não tenha sido apanhada ${ }^{28}$,

14) tendo sobrevindo sobre ele um espírito de ciúme, enciumando-se de sua mulher, e ela tenha se tornado impura, ou, sobrevindo-lhe um espírito de ciúme, enciumando-se de sua mulher, mas ela não se tenha tornado impura,

15) tal homem trará a sua mulher ao sacerdote e trará sua oferenda por ela: um décimo de efá de farinha de cevada ${ }^{29}$, mas não derramará sobre ela ${ }^{30}$ óleo $^{31}$ e não colocará sobre ela

${ }^{24}$ Op. Cit., p. 68.

${ }^{25}$ Op. Cit..

${ }^{26}$ A expressão "שכבת-זרע" é traduzida por "cópula de semente" por Chouraqui e por "dormiu maritalmente", pela Bíblia de Jerusalém. A TEB traduz simplesmente por ter "relações".

${ }^{27}$ Seguimos aqui a tradução de Friedman.

${ }^{28}$ As bíblias consultadas seguem de perto tal entendimento: "sem que tenha sido surpreendida no ato" (Bíblia de Jerusalém), ou ainda, "tenha sido surpreendida em flagrante" (TEB). A tradução veiculada na versão do Chumash coloca, da mesma forma, "e ela não for surpreendida", mas com outro sentido, isto é, ela não foi "coagida" ou "forçada", contra a sua vontade. Rashi cita então Dt 22, 28, comparando o trecho a casos de estupro, dando outra dimensão ao versículo, ou seja, a consciência e a vontade da mulher em realizar o ato ilícito (Chumash, p. 24). A tradução do "A Modern Commentary" está mais de acordo com essa visão de Rashi: "the fact that she has defiled herself without being forced", ou seja "she had not been raped" (essa última citação, em nota; nesta mesma nota o comentarista lembra que existe uma outra opção, a que, na verdade, seguimos: "without being discovered in the act"; PLAUT, 1979, p. 46).

${ }^{29}$ As interpretações talmúdicas desse v., comentadas por Rashi, são bastante severas contra a mulher suspeita: "FARINHA. Que não seja da [farinha] fina. CEVADA. E não trigo (Sotah 12); ela agiu como um animal, e sua oferenda será um alimento de animal." (Chumash, p. 24).

${ }^{30}$ Refere-se à oferenda e não à mulher. O hebraico é bastante claro, já que "oferenda" - קרבן - é um termo masculino e é representado, portanto, por um pronome masculino, evitando qualquer confusão de que aqui pudesse haver uma referência à mulher. 
incenso $^{32}$, porque é uma oferta de ciúmes, oferta de memória, recordando uma iniquidade ${ }^{33}$.

16) Então o sacerdote fá-la-á aproximar-se e a fará postar-se diante de YHWH.

17) Então o sacerdote tomará águas santas ${ }^{34} \mathrm{em}$ um recipiente de barro ${ }^{35}$ e o sacerdote tomará do pó ${ }^{36}$, que é do chão do Tabernáculo, e o porá nas águas.

18) Em seguida, o sacerdote colocará de pé a mulher diante de $\mathrm{YHWH}^{37}$ e soltará os cabelos da cabeça da mulher ${ }^{38}$ e porá em suas mãos a oferta de memória ${ }^{39}$, que é a oferta

31 O desprezo por tal mulher seria mais uma vez evidenciado, em conformidade com outras interpretações mencionadas acima: "Para que sua oferenda não seja embelezada, pois o azeite é chamado de luz, e ela agiu no escuro." (Op. Cit.).

${ }^{32}$ O comentário de Rashi continua: "Porque as Matriarcas são chamadas de "לבונה"- "incenso", como está dito (Cântico dos Cânticos 4, 6): 'para a colina do incenso' - e ela se desviou do caminho das matriarcas." (Op. Cit.). É irônico, no entanto, que a passagem escolhida para reiterar a crítica à mulher seja exatamente retirada do Cântico dos Cânticos, praticamente o único livro bíblico em que a relação de amor e de intimidade sexual entre homem e mulher, fora do casamento (mas não em adultério), é descrita sem nenhum vestígio de recriminação ou julgamento. Inclusive o termo incenso, no Cântico, é, provável e ironicamente no que se refere ao nosso caso, uma metáfora lírica ao órgão sexual feminino. Por outro lado, esses comentários, levantados ou lembrados por Rashi, geram a impressão de que a mulher já foi julgada e condenada por ter sido desprezível o suficiente para que seu marido se enciumasse e se visse obrigado a levá-la ao Templo (ou à Tenda), perante o sacerdote. É interessante nesse ponto a - de certa forma estranha - afirmação do "A Modern Commentary": "As in all situations involving private or public trust, the parties must not only be faithful but also appear to be worthy of confidence." (PLAUT, 1979, p. 51 - grifo do próprio autor).

${ }^{33}$ Outras traduções: "uma oferenda de memorização, em memória de um erro" (Chouraqui), "a meal offering of remembrance which recalls wrongdoing" ("A Modern Commentary"), "uma oblação comemorativa que deve trazer à memória um pecado" (Bíblia de Jerusalém), "uma oferenda de denúncia, que delata uma falta" (TEB) "oblação de recordação, que recorda o pecado" (Chumash).

${ }^{34}$ Rashi cita Ketubot 72, para informar que essas águas eram santificadas no kior (uma bacia de bronze) que ficava no Templo. No entanto, continua explicando que este havia sido confeccionado com o bronze dos espelhos das mulheres que uma vez haviam oferecido seus sacrifícios à entrada da Tenda de Reunião (cf. Ex 38, 8). Essas mulheres, segundo Rashi, haviam sido fiéis a seus maridos no Egito (onde, de acordo com ele, mantinham suas relações debaixo das macieiras!), enquanto a mulher aqui julgada, supostamente, não se mantivera fiel. Por isso, deviam ser testadas através dessa água (Chumash, p. 24).

${ }^{35}$ Sotah 7 interpreta, de forma bastante midráshica, como temos percebido ao longo desse comentário à tradução, que, por haver a mulher dado de beber a seu amante em copos finos, agora teria de tomar águas amargas de uma "desprezível peça de barro." (Op. Cit.).

${ }^{36}$ Rashi questiona-se, então, o motivo de a mulher ser testada pela água e pelo pó. Ele busca a resposta na criação do mundo por Deus: "Porque o início de sua criação foi pela água e pelo pó, e também porque estes são testemunhas, como está dito (Deuteronômio 30, 19): 'tomo hoje por testemunhas, sobre vós, os céus e a terra.'” (Op. Cit, pp. 24-5). Como a mulher não tem um "testemunho humano", seriam, assim, convocados o céu (donde vem a água?) e a terra.

${ }^{37}$ Para Rashi (Chumash, p. 25), a repetição da ação descrita no v. 16 quereria dizer que o sacerdote deveria "cansar" a mulher, fazendo-a andar de um lado para o outro a fim de confundi-la para que ela, enfim, "confessasse"!

${ }^{38}$ O verbo "פרע" traz alguma dificuldade para sua exata tradução. Para a TEB, o cabelo da mulher é "desgrenhado" pelo sacerdote, enquanto para a Bíblia da Ave-Maria e para o Chumash, ele descobriria o cabelo (mais especificamente, Rashi descreve que são as tranças que seriam desmanchadas, e acrescenta: "para que ela se envergonhasse" - Op. Cit.). Sigo tradução da Bíblia de Jerusalém (Chouraqui tem proposta semelhante). É esse autor quem explica que, embora não haja uma ligação direta, é este versículo que é citado quando se quer basear "biblicamente" o costume das mulheres judias religiosas de cobrirem a cabeça (Chouraqui, 1997, p. 65). Rashi comenta que daí se depreende que é vergonhoso para uma mulher descobrir a cabeça (Chumash, p. 25). É impossível, contudo, tirar conclusões mais precisas sobre o período bíblico, como, por exemplo, o modo como eram amarrados ou cobertos seus cabelos e se era um costume apenas entre as mulheres casadas, sendo talvez até 
de ciúmes, e na mão do sacerdote estarão as águas das amarguras (amargas) e das maldições ${ }^{40}$.

19) Então o sacerdote fará a mulher jurar, e dirá a mulher: "Se um homem não se deitou contigo e se não te desviaste tornando-te impura sob (a autoridade $\mathrm{de}^{41}$ ) teu marido, permaneça (lit.: seja) limpa ${ }^{42}$ dessas águas das amarguras e das maldições.

20) Porém, se tu te desviaste sob teu marido e te tornaste impura e esteve um homem contigo em seu leito (o do marido) que não o teu marido,

21) - o sacerdote fará a mulher fazer um juramento de imprecação e dirá o sacerdote à mulher: - YHWH te coloque por imprecação e juramento ${ }^{43}$ no meio do teu povo e faça cair a tua coxa e inchar o teu ventre ${ }^{44}$

mesmo um símbolo de seu estado. O que nos parece claro, entretanto, é que certamente tal procedimento era visto como um ato de humilhação social, religioso e pessoal contra essa mulher.

${ }^{39} \mathrm{Na}$ tradução de Friedman, "trazendo à memória".

${ }^{40}$ Rashi procura enfatizar que não são as águas que são malditas, desde que são sagradas, mas que, sim, têm o poder de amaldiçoar (Op. Cit.). Deva-se talvez acrescentar que, exatamente por serem águas sagradas e puras, seu poder é de amaldiçoar aqueles que estão impuros. O "A Modern Commentary" questiona se essas águas seriam realmente amargas ou se é uma linguagem figurativa. Reforça, entretanto, que não são as águas em si que punem a culpa, mas sim Deus (PLAUT, 1979, p. 47).

${ }^{41}$ A Bíblia de Jerusalém acrescenta "sob domínio".

${ }^{42}$ Da raiz de "limpar". No sentido de "não te façam nenhum dano" (Schökel), "não te façam mal" (Bíblia Ave-Maria), "sejam inofensivas" (Bíblia de Jerusalém), "sejas preservada" (TEB), "esteja livre" (Chumash), "be immune to harm" ("A Modern Commentary"), "sejas inocente" (Chouraqui). Nossa escolha baseia-se na ideia de que, sendo a mulher inocente (pura/limpa), seu estado permanecerá o mesmo (estará preservada, como coloca a TEB), ou seja, continuará pura.

${ }^{43}$ Segundo a TEB, "exemplo que se cita nas imprecações e nos juramentos", enquanto a Bíblia de Jerusalém traz "te faça objeto de imprecação e maldição".

"את־ירכך נפלת ואת־בטנה צבה" Duas expressões de difícil entendimento. As opções são múltiplas: "murchar o teu sexo e inchar o teu ventre" (Bíblia de Jerusalém), "a tua coxa cair e o teu ventre inchar" (Chumash; semelhantemente, Chouraqui), "your thigh to sag and your belly to distend" ("A Modern Commentary"), "teu seio definhar e teu ventre inchar" (TEB), "emagrecer os teus flancos e inchar o teu ventre" (Bíblia Ave-Maria). O dicionário Schökel especula: "afrouxar-se as coxas esterilidade?, impotência?" (cf. vocábulo "רךך", p. 296). A opção escolhida pela Bíblia de Jerusalém, qual seja, "murchar o sexo", parece, em nosso entender, a que deixa mais explícito o sentido da expressão. As demais traduções, mais literais na verdade, parecem tender para uma linguagem de eufemismos (ex.: teu seio definhar - TEB), que pode ser exatamente a linguagem bíblica utilizada caso "ירך" - "coxa" - for assim entendido, ou seja, como um eufemismo para o órgão sexual feminino (o termo certamente aparece como um eufemismo na Bíblia, mas com relação ao órgão masculino; cf. Gn 24, 2). O "A Modern Commentary" acredita ser este o caminho para o entendimento da expressão: "“Thigh' is probably a euphemism for the sexual organ... The expression might also refer to dropsy of the ovaries, thus implying the threat of sterility" (PLAUT, 1979, p. 48). Está se falando, de qualquer maneira, de uma forma de "impotência" feminina, como é colocado, em forma de pergunta, por Schökel. Nossa opção por "cair tuas coxas", mais literal, seguindo o Chumash, embora não rejeite a ideia de que seja um eufemismo, enfatiza a questão da perda de força, de vigor sexual, levando, sim, a uma espécie de impotência. Ou seja, o propósito seria cortar "o mal" pela raiz ao trazer, com a maldição, o fim da vida sexual da mulher adúltera (com a finalidade de que não procrie). Rashi comenta: "Na maldição antecipou a coxa antes do ventre, porque através dela começou a transgressão" (Chumash, p. 25). Outro argumento a favor dessa explicação é a expressão popular hebraica " נפל על ברך" (cair sobre os joelhos), simbolizando a perda de toda a força, de todo o vigor, a prostração ou o desfalecimento. O livro de Jó parece conter uma confirmação para a noção de que o pecado leva à impotência. Patai descreve o texto "He describes in considerable detail the terrible consequences of sinning. He states that the sinner, whom he calls the "wicked', loses his sexual powers." (Jo 18, 5-21; cf., da mesmo forma, Jó 20 e Jó 27, 14 - PATAI, 1959, p. 82-3). A segunda expressão, "צטנך צבה", é evidentemente menos complexa linguisticamente. Uma opção para o termo "צבה", levantada por Schökel, é "inflamar-se". Assim, tudo parece apontar para um ritual de maldição que visava trazer esterilidade à mulher adúltera. Assim, não acreditamos que as duas expressões sejam formas diferentes 
22) e penetrem essas águas das maldições em tuas entranhas para inchar o ventre e cair a coxa", e dirá a mulher: "Amén, Amén!"

23) O sacerdote escreverá essas imprecações no livro e apagará com as águas das amarguras ${ }^{45}$

24) e fará com que a mulher beba as águas das $\operatorname{amarguras}^{46}$ e das maldições para amargura ${ }^{47}$.

25) O sacerdote, então, tomará das mãos da mulher a oferta dos ciúmes e ergueráa ${ }^{48}$ a oferta diante de YHWH e a fará aproximar-se do altar ${ }^{49}$.

26) O sacerdote tomará um punhado da oferta, o memorial dela ${ }^{50}$, e queimará (sobre) o altar. Depois fará que a mulher beba as águas

27) e, tendo bebido as águas, se ela estiver impura e tiver sido infiel a seu marido, penetrará nela as águas amaldiçoadas para amargura e inchará seu ventre e cairá sua coxa e a mulher será por imprecação no meio de seu povo.

28) No entanto, se a mulher não estiver impura, mas pura, ela estará limpa ${ }^{51}$ e será fecunda. ${ }^{52}$

29) Essa é a Torá dos ciúmes quando uma mulher desviar-se sob seu marido e ficar impura

de dizer o mesmo, mas duas etapas consecutivas em que se acrescia o castigo da esterilidade ao da perda do vigor sexual. Rashi questiona-se se a maldição vale somente para a mulher ou também para aquele que com ela cometeu o adultério (Chumash, Op. Cit.). Não há nada na passagem que o indique. ${ }^{45}$ As palavras inscritas no livro não são meramente "apagadas" no sentido de que desapareceriam, mas, na verdade, são absorvidas pelas águas que se impregnam do "poder" da palavra, principalmente o da palavra escrita. O poder e a eficácia da palavra pronunciada ou escrita são evidentes em todo o texto bíblico. Basta lembrar da passagem em que é solicitado ao profeta Ezequiel que "coma" do rolo vindo do céu, que continha as palavras divinas (Ez 2, 9-3,3), entre tantas outras que poderiam demonstrar essa crença arraigada. O "A Modern Commentary" considera a possibilidade de se haver misturado dois rituais diferentes, sendo que um deles consistiria exatamente nesse que se descreve entre os vv. 22 e 26 (PLAUT, 1979, p. 48).

${ }^{46}$ Rashi levanta aqui, indiretamente, a questão de que a mulher estaria sendo obrigada a beber, contra a vontade, das águas amargas. Os verbos, sempre na forma Hif'il (usada para verbos causativos), que descrevem toda a relação entre sacerdote e mulher, parecem indicar tal imposição. Todavia, outra opção seria que, eventualmente, esta consistiria uma linguagem imperativa endereçada ao sacerdote para o cumprimento correto do ritual, já que é um procedimento a ser seguido em diversas etapas (talvez algo semelhante a um "manual"?).

${ }^{47}$ Segundo a Bíblia de Jerusalém, "serão para ela amargas".

${ }^{48}$ Seguindo a Bíblia de Jerusalém. Outras opções são: "balançará" (Chumash e, semelhantemente, Chouraqui), "agitá-la-á" (Bíblia Ave-Maria), "wave" (“A Modern Commentary") e "apresentá-la-á" (TEB). Os dicionários contemplam, de uma maneira ou de outra, todas as alternativas propostas por nossas versões. Por conseguinte, é difícil precisar a ação exata a ser executada pelo sacerdote.

${ }^{49}$ No período do Segundo Templo, essa cena seria, aparentemente, impossível. As mulheres deviam ficar em um pátio intermediário entre o pátio dos estrangeiros e judeus em estado de impureza e aquele dos homens leigos; de qualquer maneira, bem distantes do altar. O Talmud relata que, no período, esse ritual acontecia à porta de Nicanor (Sotah 8b).

${ }_{50}$ Memorial de seu "suposto" ato ilícito. TEB e Bíblia.Ave-Maria.: "como memorial" e, Bíblia de Jerusalém, "para memorial".

${ }^{51}$ Seguem outras traduções levantadas: "será inocentada" (TEB; semelhantemente, Chouraqui), "sairá ilesa" (Bíblia de Jerusalém), "será preservada" (Bíblia Ave-Maria), "será absolvida" (Chumash). Optamos por manter na tradução o significado original da raiz hebraica; de qualquer maneira, o sentido está bem claro.

${ }^{52}$ Seria uma bênção? O "A Modern Commentary" traduz por "retain seed" e explica que a mulher inocentada poderia então receber uma bênção em compensação ou desagravo por ter passado por tais humilhações sociais, religiosas, morais e pessoais. Uma outra interpretação mencionada é a de que essa mulher estava então apta a voltar para seu marido (PLAUT, 1979, p. 46). Chouraqui traduz por "semeada de semente", bem como Friedman "conceberá uma semente". A Bíblia Ave-Maria traz "terá filhos", enquanto lemos "será fecunda" na Bíblia de Jerusalém e na TEB. Enfim, ela está apta para ter descendência entre os filhos de Israel. 
30) ou um homem quando vier sobre ele um espírito de ciúmes e enciumar-se de sua mulher e apresentar a mulher diante de YHWH: o sacerdote aplicará nela todo esse procedimento $^{53}$

31) e o homem ficará limpo ${ }^{54}$ da falta, enquanto aquela mulher carregará sua falta.

O texto trata de uma antiga forma de ordálio ${ }^{55}$, com raízes mágicas, provavelmente préjavistas, que ganharam contornos monoteístas ${ }^{56}$. Bird bem percebe nos textos bíblicos aquilo que nessa passagem parece evidente, ou seja, a autoridade legal do homem sobre a mulher ${ }^{57}$, inclusive na esfera privada, naquele que seria seu ambiente primário de ação e apoio, sua família. Segundo a autora,

moreover, since the legal and religious institutions that give expression to the society's values and attempt to regulate behavior belong to the public sphere and are designed and governed by men, the values they articulate and seek to enforce are essential male values, though formulated in general or universal terms. Thus asymmetry between the primary spheres of male and female activity has the character of encapsulation and penetration of the domestic sphere by the public sphere, ${ }^{, 58}$.

53 No texto hebraico, o termo traduzido aqui por "procedimento" é, na verdade, "Torá". "Procedimento" foi escolhido por descrever mais fielmente, a nosso ver, as diversas etapas "rituais" a serem cumpridas pelo sacerdote (e pela passiva suspeita).

${ }^{54}$ Novamente com sentido de "estar inocente". Rashi levanta duas explicações para a afirmação. Uma seria de que o homem não seria culpado ou castigado caso a mulher morresse devido à ingestão das "águas amargas". A outra diz que, sendo a mulher inocentada, esse homem poderia receber novamente sua mulher, já que o marido de uma Sotah é proibido, pela Lei, de voltar a relacionar-se com ela (Chumash, p. 27). Uma terceira explicação talvez possa ser a de que o homem cumpre seu dever ao levar sua mulher suspeita de adultério perante a divindade, não pesando, por omissão, o pecado dela sobre ele.

${ }^{55}$ Chouraqui coloca que é um caso de ordálio invertido, ou seja, ao invés de se "procurar" obter, através de meios naturais, uma comprovação da inocência do julgado, aqui se busca saber se ele é culpado. A divindade, então, pronuncia-se por meio de tal método (Chouraqui, 1997, p. 62). O “A Modern Commentary" comenta os variados paralelos encontrados em diversas culturas até a Id. Média, como entre romanos, gregos, hititas, babilônios e africanos (PLAUT, 1979, p. 50; este, bem como CHOURAQUI, 1997, p. 63, mencionam o paralelo com o código de Hamurabi § 131-132).

${ }^{56}$ Brenner recorda algumas práticas mágicas sacerdotais, como é o caso da cerimônia da novilha vermelha (Nm 19) ou do ritual de purificação de doenças de pele (Lv 13-14). Certamente pode-se relacionar $\mathrm{Nm} 5$ entre essas práticas antigas, herdadas de uma religião hebraica pré-monoteísta (ritualmente semelhante a outras práticas rituais sacerdotais, mas, ideologicamente mais próxima da maldição jogada por Eliseu sobre os meninos em 2Rs 2, 23ss). Brenner explica a questão: "Os magos estavam proibidos de se envolver na própria arte, mas aos membros do culto oficial tal prática era permitida. Desse modo, algumas práticas foram alçadas de seu contexto pagão original - mas muito freqüentemente pertenciam também à esfera religiosa - e legitimadas, divorciando-se de suas origens e tornando-se propriedade do contexto (supostamente ortodoxo) religioso." (Brenner, 2001, p. 100).

${ }^{57} \mathrm{O}$ "A Modern Commentary" é enfático sobre este ponto ao comentar sobre Nm 5: "The Torah gives the male partner clear prerogatives by laying the burden of proof of innocence on the woman. And, while both the wife and her adulterous lover were subject to capital punishment if guilty (Lev. 20:10; Deut 22:22), no reverse ordeal was instituted: a wife suspecting her husband of infidelity had no recourse. The standards were not the same [...]" (PLAUT, 1979, p. 50).

${ }^{58}$ BIRD, 1997, p. 57. Embora enfatize posteriormente que, com exceção das leis sobre os votos religiosos e sobre suspeita de adultério, não haveria mais referências ou indícios de um envolvimento da Lei na esfera intrafamiliar. 
A religião e o rito, como vemos aqui em $\mathrm{Nm}$, oferecem suporte, legitimidade, mecanismos práticos e um formato discursivo autoritativo para o funcionamento legal desse sistema.

Segundo Fuchs, isso se deveria à ideologia patriarcal bíblica que “...seeks to naturalize and legitimate man's political dominance.” (Fuchs. In: Bach, p. 128). Bird, entre outros autores, faz notar que as leis são quase que exclusivamente endereçadas para o homem ${ }^{59}$ e que os interesses familiares identificam-se com aqueles do chefe do clã ${ }^{60}$, como percebemos nessa lei rito-sacerdotal. Nesse sentido e acrescentando, como vimos anteriormente, toda a importância que se dava a uma linhagem pura e legítima, podemos entender que o adultério em Israel é um crime de "primeira magnitude na lei israelita", tratado com o mesmo rigor que, por exemplo, o homicídio, demandando igualmente a pena capital ${ }^{61}$. Posteriormente Bird comenta, citando exatamente essa passagem de $\mathrm{Nm}$ 5:

Patrilineal and patriarchal interests demanded exclusive right for men to their wives sexuality. A woman sexuality was consequently guarded before marriage by her father ${ }^{62}$ (Deut 22:13-21, 28-29; cf. Gn 34:5-7) and after marriage by her husband (Num 5: 11-31). Adultery was the most serious of women's crimes, though both partners received the same sentence-death (Lev 20:10; Deut 22:22) ${ }^{63}$.

\footnotetext{
${ }^{59}$ Op. Cit, p. 21. Nota-se o lugar especial do homem adulto, não apenas na sociedade laica, mas na religião também (em geral, ele é o único membro pleno do grupo): a circuncisão, símbolo da pertença religiosa e nacional, refere-se ao homem e transmite-se (isto é, a continuidade da religião e da nação) unicamente através dos filhos homens. Da mesma forma, exclusivamente homens da estirpe de Levi são sagrados sacerdotes. Contudo, toda a família de sacerdote deve seguir as prescrições específicas para a classe sacerdotal. As leis contra contaminações sexuais são mais severas para membros da família do sacerdote (ex., Lv 21, 9; v. também 22, 10-14). P apontou para uma igualdade entre os sexos na narrativa da criação ao compor uma simultaneidade na criação do homem e da mulher, ambos imagem de Deus. Porém, não desenvolveu ou levou adiante tal ideal. O contraste entre esse primeiro movimento igualitário e as leis ou outras narrativas, mesmo sacerdotais, é evidente. Bird reflete: "The $\mathrm{P}$ formulation implies an essential equality of the two sexes. But its implications were only partially perceived by the priestly writer, whose own culturally determined ideas concerning appropriate roles and activities of men and women generally fail to reflect this insight. Thus male genealogies and an exclusively male priesthood dominate the rest of his work." (Op. Cit., p. 87, Nota 87).

${ }^{60}$ Op. Cit., p. 23. A autora cita alguns exemplos de leis voltadas para o direito dos dependentes, como Dt 21, 10-4; contudo, não é o caso da lei que analisamos (além do fato de esta ser uma lei deuteronomista e não sacerdotal).

${ }^{61}$ Op. Cit., p. 21. Cf. Lv 20, 10. O homem que fosse pego em adultério com uma mulher casada teria o mesmo destino da mulher: a morte. Ele, provavelmente, é condenado por voltar-se contra um código de honra entre homens, que se reflete na lei, e por falhar em sua responsabilidade, como israelita, de manter a ordem social, que está contida na ordem divina e cósmica. Parece que houve algum período em que a punição não era tão rigorosa, pelo menos no período de Oseias ou Jeremias (cf. Jr 3, 8 e Os $2,2-7$ ), pois, pelo que os textos indicam, o adultério levava simplesmente ao divórcio. Chouraqui, ao analisar o texto de $\mathrm{Nm} \mathrm{5,} \mathrm{toma} \mathrm{por} \mathrm{pressuposto} \mathrm{que} \mathrm{a} \mathrm{questão} \mathrm{aqui} \mathrm{é} \mathrm{de} \mathrm{um} \mathrm{suposto} \mathrm{direito} \mathrm{do} \mathrm{marido}$ de divorciar-se ou rejeitar a mulher unilateralmente. Assim, em sua visão, o autor acredita que este ritual funcionava como uma proteção para a mulher que poderia então provar ser inocente e evitar ser repudiada sem qualquer forma de processo (CHOURAQUI, 1997, p. 62).

${ }_{62}$ Ou irmãos, como parecem demonstrar Simeão e Levi, no caso de Dina (Gn 34).

${ }^{63}$ BIRD, 1997, p. 61.
} 
Assim, apenas o homem é considerado um membro pleno da sociedade e uma pessoa responsável ${ }^{64}$. Ele é responsável não somente por seus próprios atos, mas também por de seus dependentes, isto é, sua mulher, filhos, servos etc. Podemos pensar, entretanto, que, como responsável perante Deus e a sociedade, o homem que suspeitasse de sua mulher teria não apenas o direito, mas também a obrigação de levá-la ao julgamento acima prescrito. Sendo ela considerada culpada, é retirado do marido o dever de responsabilidade sobre ela, como lemos no versículo $31^{65}$; o homem sai limpo, mas a mulher carregaria sua falta. Bird nota que, exceto nos casos de ofensas sexuais, da ausência de homens (pai, irmão ou marido), de alguma questão sócio-econômica extraordinária ou, ainda, da necessidade de proteção para viúvas, a mulher praticamente não existe para o sistema elaborado de leis ${ }^{66}$. Nesse trecho de

${ }^{64}$ Segundo Brenner, a mulher é, de modo geral, definida pelas Escrituras como um ser inteligente, mas irresponsável e necessitada de proteção (ver BRENNER, 2001, p. 196; contudo, o tema é uma constante no livro da autora. Cf., p. ex., a interessante análise das narrativas de criação a partir da p. $181)$.

${ }^{65} \mathrm{Cf}$. os comentários elaborados em nota sobre o texto concernente.

${ }^{66}$ BIRD, 1997, p. 30. Lembrando, no entanto, que, apesar de endereçadas primeiramente a homens, muitas leis religiosas referentes à prática e à pureza ritual, deviam ser observadas por todos. $\mathrm{O}$ endereçamento a "אדם" ("Adam" = Adão), nas leis sacerdotais, não deve ser restringido ao "homem", no sentido de que só o sexo masculino era implicado. É bom lembrar que, na narrativa sacerdotal da criação, Deus criou "אדם" a sua imagem e semelhança , "זכר ונקבה ברא אותם" (macho e fêmea os criou"; Gn 1, 27). Sendo assim, pelo menos dentro do pensamento e do uso terminológico sacerdotal, "אדם" significa "ser humano", podendo ser homem ou mulher. Seu significado seria um pouco diferente na narrativa J da criação (Gn 2), em que o homem é denominado "אדם", em contraste com a mulher "חוה" (Hawah, ou seja, Eva, da raiz da palavra "vida"). Chama a atenção um dos Manuscritos do Mar Morto, em sua maioria escritos entre o I séc. a.C. e I d.C., denominado Documento de Damasco, que afirma categoricamente: "E a lei das relações sexuais proibidas foi escrita para homens, mas, como para eles, para as mulheres; assim, se a filha do irmão descobre a nudez do irmão de seu pai, ela (=a sobrinha) é uma relação (proibida) de parentesco." (CD V, 9-11; trad. da autora). Os sacerdotes líderes de Qumran, portanto, não se atrelavam apenas a uma interpretação literal da lei, que proibia que a tia tivesse relações ou se casasse com o sobrinho (cf. Lv 18, 13). Assim, compreendiam que a lei devia ser imposta a ambos os sexos. Os rabinos, no entanto, já se restringiram ao literal da lei, vetando apenas casamento entre tia e sobrinho e aprovando entre tio e sobrinha. Schiffman comenta: "Later rabbinic texts inform us that the Pharisaic-rabbinic tradition considered it permitted - even praiseworthy - to marry ones's niece" (cf., no Talmud bibilônico, Yebamot 62b; SCHIFFMAN, 2001, p. 271). Sobre a lei do Documento de Damasco, Grossman analisa: "This passage stands out in the text for its presentation of a woman as a sexual actor (one who 'uncovers nakedness' in a sexual relationship), a role otherwise attributed only to men. However, the reversal of action and passivity is hardly complete here. The woman 'uncovers nakedness', but it is she, and not the man, who is the forbidden close relation (והיא שאר = "ela é uma relação proibida de parentesco". Lit.: "ela é carne"). As such, she is the one who is presented as sexually unavailable and unacceptable for marriage, in the larger androcentric context of the text's scriptural sources. In addition, it is interesting to note that this potential actor is nowhere a 'woman' (except in the text's explanation of its exegetical process); instead, she is 'a [man's] brother daughter' or, in the case of the quotation of Leviticus, 'a [man's] mother's sister.' Rather than focusing on women as actors, this text makes its androcentric assumptions clear in an exegetical tactic that ultimately confirms the passive and secondary role of women with respect to the normative male covenanter (=membros do movimento que escreveu os textos sectários dentre os Manuscritos do Mar Morto)." (GROSSMAN, 2004, p. 221). Grossman tem razão em muitas de suas conclusões, e talvez pudéssemos relativizar algumas, porém, uma coisa parece certa, esses sacerdotes consideravam que a lei mosaica, de modo geral (p. ex., podemos excetuar aquelas leis específicas a um dos gêneros, como as leis relativas à 
Nm, por sua vez, ouvimos a voz da mulher uma única vez, ao falar, passivamente, "Amén, Amén"67. De resto, acompanhamos seus movimentos dirigidos pelo sacerdote (assim como as suas únicas palavras). Essa imagem destoa da imagem da mulher nas narrativas das Escrituras. Ela é descrita como inteligente, persuasiva, capaz, astuta, determinada e, muitas vezes, portanto, perigosa ${ }^{68}$ para os homens, que deviam atentar-se para não caírem em armadilhas. De acordo com Bird, o casamento, o estágio mais íntimo da relação homemmulher, representa, por isso mesmo, a situação de maior perigo para o homem ${ }^{69}$. Para a autora, essa subordinação pode refletir estruturas formais do poder social masculino, porém

it is an inadequate measure of women's actual power or even recognized authority. Hints of the wider influence and power exercized by women in Israelite life may be seen in the Old Testament's literary presentation of women, which depicts them as more complex and forceful than their legal status suggests and gives them leading roles in some of the critical dramas ... The expanded role of women in literature, however, especially in family sagas and novellas, reflects artistic need as well as lived reality. Behind this need is a more general pattern symbolization, exhibited in linguistic as well as literary forms.

A autora nota uma diferença fundamental entre as leis do antigo Israel e dos demais povos da região, qual seja, a severidade com que são tratados os crimes sexuais:

Israel's laws differ most notably from other known law codes in their unusual severity in the field of sexual transgression and in the severity of the religious laws that prescribe and seek to preserve the exclusive and undefiled worship of Yahweh, the national deity. These two unique features are interrelated and both had significant consequences for women in ancient Israel. ${ }^{70}$

Como vimos em nosso estudo sobre os versículos de Lv 20, podemos concluir com a autora, que, diferentemente dos povos vizinhos de Israel, "sexual offenses are religious offenses in Israel. They are not private matters, but matters of vital concern to the whole community."71. Isso se percebe claramente nos dois textos lidos, seja em Lv ou em Nm, pois, no primeiro, surge como uma questão social e religiosa importante excluir do grupo qualquer possível descendência provinda de relação ilícita, assim como, na segunda perícope, é

purificação da mulher após o parto ou do homem com fluxo genital), valia para os dois sexos e devia ser obedecida por homens e mulheres.

${ }^{67}$ V., p. ex., as narrativas referentes às matriarcas de Israel no livro de Gênesis ou as muitas figuras femininas no livro de Juízes (p. ex., Débora, que foi uma das juízas de Israel, em Jz 4), além de algumas que dão nome a livros, como é o caso de Rute, Ester ou Judite. Bird comenta: "The Old Testament is the product of a patriarchal world, and more specifically, of a literate, urban elite of male religious specialists, ... whose views created or reflect the dominant theological perspectives. Women in the biblical texts are presented through male eyes, for purposes determined by male authors. ... women are not heard directly in the biblical text, in their own voices, the Old Testament gives no unmediated access to the lives and thought of Israelite women." (BIRD, 1997, p. 53).

${ }^{68}$ V. 2Sm 14, 1-20; 20, 16-22; 1Rs 1, 11-31.

${ }^{69}$ BIRD, 1997, p. 38-9.

${ }^{70}$ Op. Cit., p. 20.

${ }^{71}$ Op. Cit., p. 21, Nota 11. 
importante identificar adúlteras, excluí-las de seu lar e do grupo, puni-las e humilhá-las, fazendo delas um exemplo sócio-religioso, procurando, através do ritual, evitar que procriem em Israel $^{72}$. Esses casos são vistos como uma ameaça à estabilidade social e religiosa ${ }^{73}$ em seu ataque contra a aliança, à pureza da descendência santa de Israel e, numa instância mais ampla, da segurança do povo na terra ${ }^{74}$ e da ordem cósmica. É considerado premente que tal mal seja exterminado do meio do povo, inclusive, em determinados casos, através da pena capital dos culpados, para que a terra não se contamine e não acarrete a cólera de Deus, que a devida punição dos culpados e o ritual buscavam conter. O castigo da adúltera, ou daqueles que mantêm relações ilícitas, é intimamente correlacionado à sua transgressão, isto é, tornarse-iam, por conseguinte, estéreis. Nas palavras de Patai, "in this outlook, it is almost

${ }^{72}$ Uma família numerosa, com muitos filhos homens é o que assegurava continuidade ao nome do pai, - Chwarts lembra que é a ascendência que confere identidade dentro dessa sociedade, uma vez que as pessoas se conheciam pelo nome em associação com o nome do pai, os quais se conectam pela partícula "ben" (filho) ou "bat" (filha) (CHWARTS, 2004, p. 38) - conferindo status ao pai de família. Brenner, lembrando casos como o de Tamar (Gn 38), faz notar que até mesmo atos considerados tabus são tolerados a fim de se garantir continuidade e posteridade, concluindo que, para a sociedade israelita, esse é um valor supremo (BRENNER, 2001, p. 195). Bird lembra que é o cumprimento de tal tarefa que garantia à mulher seu espaço na família e um lugar social para ela. A mulher encontra honra semelhante à conferida ao homem e maior segurança social e em seu casamento através da maternidade (BIRD, 1997, p. 28-9). A autora diz posteriormente: "Only in her role as mother is she accorded status and honor equivalent to a man's.", mas sempre sob a autoridade de algum homem: pai, irmão ou marido (exceção para viúvas e divorciadas; Op. Cit., p. 30). Para ela, esse seria um sistema de recompensa: "The actual status of women is exceedingly difficult to judge in a patriarchal and patrilineal society, where systematic bias in favor of the male characterizes language, laws, and most formal structures and relationships. The compensation that necessarily exists in such a system is rarely visible in formal documents and is hard to assess. Whether formalized or informal, it generally serves to reinforce the system by making it bearable for those discriminated against. Thus the honoring of the mother is a necessary compensation, since the mother's role is an essential one to the maintenance of the society. Informal compensation is represented in the 'underhanded' tactics used by women to get their way. But significant attempts were also made in Israel, against prevailing cultural norms, to recognize women as equals in the covenant community." (cf., p. ex., Jl 2, 28; Jr 31, 22; Os 4, 14 - Op. Cit., p. 45, Nota 83). Segundo a autora, o adultério transtorna essa relação e o pior castigo para a mulher (avaliada basicamente por seu potencial procriador), a esterilidade, é almejado através de um ritual como o que vemos em Nm. A mulher inocentada, como vimos e nos é mostrado em um ponto mais adiante no texto, deve ser recompensada de sua humilhação. Isso se faz através de uma bênção para torná-la ainda mais honrada do que antes, tornando-a mãe. O futuro da mulher considerada culpada é a exclusão social e religiosa e a humilhação, semelhante a que já sofriam as mulheres estéreis (ameaça de divórcio, marginalização social, perigo de viuvez sem qualquer amparo, sendo vista como uma desfavorecida pela própria divindade), mas ampliada pelo estigma social de ser "objeto de maldição", tornando-se, provavelmente, pária dentro de seu povo, como é anunciado no próprio texto de $\mathrm{Nm}$. Já o homem terá oportunidade de refazer-se e construir uma nova família em Israel (v. BIRD, 1997, p. 28-9).

${ }^{73}$ Nas palavras de Brenner: "Falta de devoção matrimonial pode levar à anarquia e à demolição da estrutura comunal da qual a família é a unidade básica, e sem a sua proteção os membros da comunidade não podem sobreviver. Isso vem à tona no acontecimento final das histórias." (BRENNER, 2001, p. 167).

${ }^{74}$ Chwarts explica: "Uma das elaborações mais complexas do pensamento hebraico é a maneira como o humano polui a terra com suas transgressões aos preceitos divinos, tornando-a impura e infértil duas atribuições sociorreligiosas da mulher menstruada na sociedade israelita antiga." (CHWARTS, 2004, p. 59). 
inevitable that a causal connection be predicated between adultery and other sexual transgressions on the one hand and sterility on the other. ... an illicit sexual act prevents conception, which is the aim and purpose of all licit sexual activity" ${ }^{\prime 7}$. Ao menos para a doutrina $P$.

Alhures nas Escrituras, o adultério também é tratado com gravidade. Em Provérbios, uma má esposa é a vergonha e a desgraça de seu marido, e, por fim, para si mesma $(12,4)$. A mulher adúltera é então comparada à prostituta ${ }^{76}$, mas, ao invés de custar dinheiro (ou um pedaço de pão), custa a própria vida do marido $(6,26)$. $\mathrm{O}$ marido parece ter pleno direito à vingança em 6, 34: "Pois o ciúme excita a raiva do marido, e no dia da vingança não terá piedade...". No entanto, não há referências ao ritual e ao julgamento divino descrito em Nm. A mulher adúltera em $\operatorname{Pr} 30,20$, não reconhece, confessa ou arrepende-se de seu procedimento. A adúltera é perigosa e má, tem-se de tomar cuidado com seu linguajar enganador e persuasivo. Já o adúltero é descrito como um fraco e uma vítima tola, que se deixa levar por uma mulher em seu discurso astuto ${ }^{77}$.

De qualquer maneira, nos textos bíblicos, o adultério é a metáfora para o pior dos pecados: a apostasia contra YHWH. Para os profetas, a ingrata e apóstata Israel é a prostituta ou a adúltera (esta muitas vezes igualada à prostituta; v. Os 1-2; Jr 2, 20; 3,2; 4, 30; Is 23, 15 18; cf. também Pr 9, 13-18 ${ }^{78}$ ). Patai analisa:

In fact, all through Biblical literature, idolatry is spoken of as a collective adultery or whoredom of the people of Israel. ... The sin of idolatry was thus almost indistinguishable in Biblical mentality and phraseology from the sin of adultery. Both resulted in the same punishment: barrenness among the humans and the disruption of the normal course of the nature, the malfunctioning of its powers, drought, other natural catastrophes, and ultimately, famine and the destruction of the people. ${ }^{79}$

O próprio exílio e a destruição de Jerusalém pelos babilônios em 586 a.C. seriam vistos como consequências de tal infidelidade.

Conclusão

\footnotetext{
${ }^{75}$ PATAI, 1959, p. 80.

${ }^{76}$ A prostituta é, no entanto, tolerada. A relação sexual com prostitutas não acarreta falta grave contra a Lei. Os livros sapienciais, em geral, desaconselham e até condenam moralmente essa prática.

${ }^{77}$ Ela tem o dom da retórica e faz lembrar o papel da cobra na narrativa bíblica da queda do paraíso. Brenner define essa mulher como a "sedutora negativa": "Ceder a seu charme coloca em perigo a estrutura da sociedade, bem como a vida e bem-estar do indivíduo. Portanto, ela deve ser identificada e evitada." (BRENNER, 2001, p. 165).

${ }^{78}$ V. BIRD, 1997, p. 64-5.

${ }^{79}$ PATAI, 1959, p. 84-5.
} 
Suzana Chwarts classifica nossos dois textos como exemplos de "esterilidade institucionalizada". Ela define o que seria exatamente:

é empregada como agente punitivo e regulador da sociedade estruturada. A esterilidade funciona como punição a transgressões de ordem moral-sexual, como o incesto (Lv 20, 20) e o adultério praticado por uma mulher (Nm 5, 11-31). A exclusão do grupo e da ordem divina se dá nesse contexto. A terra, poluída pelas transgressões sexuais e pela apostasia, vomita seus habitantes, desenraizando-os. O elemento estrangeiro (por exemplo, a terra de Moab, no livro de Ruth) e o exílio são associados simbolicamente à esterilidade, à morte coletiva e ao desaparecimento. ${ }^{80}$

Por outro lado, temos conclusões diferenciadas sobre algumas questões. Para Chouraqui, o ritual descrito em Nm assemelhar-se-ia a um tipo de exorcismo do espírito de ciúme que teria "possuído" o homem ${ }^{81}$ e que todo o processo serviria como um sistema de proteção para a mulher, evitando que fosse repudiada sem o devido julgamento, enquanto que as águas seriam inofensivas ${ }^{82}$. Para a literatura feminista consultada, essa seria uma clara evidência da subordinação da mulher, de seu papel como aquela que gerará zera' (posteridade) de seu marido para Israel (ou que colocará isso em cheque) e de que, enfim, o poder constituído e suas leis teriam sido estabelecidos para os homens e em benefício e proteção da sociedade baseada na patrilinearidade. Contudo, é possível vislumbrar-se uma atuação e liberdade de decisão femininas maiores nas narrativas bíblicas (que provavelmente refletem mais eficazmente a realidade), do que a seção de leis nos permitiria perceber. De qualquer modo, é difícil afirmar com Chouraqui de que o procedimento descrito seria, em princípio, um recurso feminino de proteção social. O ritual descrito não deixa de conter sutilezas de humilhação moral, pessoal e provavelmente social, tornando-se difícil imaginar que poderia ser, p. ex., solicitado por uma mulher que desejasse provar sua inocência. Ao contrário, o procedimento é apresentado como um recurso à mão do homem com ciúme de sua mulher. Os verbos no Hif'il (ou seja, no causativo) transmitem a ideia de que nenhum movimento da mulher é voluntário e a iniciativa e ações ativas são sempre das personagens masculinas. O descobrimento do cabelo, o fazer beber da poção amarga e as imprecações conduzem igualmente a essa conclusão. Contudo, o ritual realmente podia servir para vindicar

\footnotetext{
${ }^{80}$ CHWARTS, 2004, p. 199. Pouco antes do exílio da Babilônia em 586 a.C., o profeta Jeremias denunciava ao povo seus pecados e anunciava o poder destes de subverter a ordem da criação: "E em seu coração não dirá: temamos ao Senhor, nosso Deus, que no tempo devido nos manda a chuva do outono e a chuva da primavera, e nos garante as semanas destinadas à colheita. Foram vossas iniqüidades que alteraram essa ordem, vossos pecados que vos privaram desses bens" ( $\mathrm{Jr} 5,24-5)$. O profeta, no mesmo cap., denuncia formas diversas de transgressão moral, inclusive a sexual: "Cumulei-os de dons; e eles cometem adultério, acercando-se das casas de devassidão. Garanhões bem nutridos, no calor do cio, cada qual relincha ante a mulher do próximo." (Jr 5, 8; Trad. Bíblia AveMaria).

${ }^{81}$ CHOURAQUI, 1997, p. 67.

${ }^{82}$ Op. Cit., p. 62-3; v. nota 61 acima.
} 
mulheres que, sem ele, seriam simplesmente repudiadas e estigmatizadas sem direito a qualquer amparo material.

Já para Patai, por exemplo, as leis de Lv e Nm refletiriam mais uma crença popular de que relações ilícitas "causariam" esterilidade ${ }^{83}$. Eilberg-Schwartz, por sua vez, procura descobrir o que há de doutrina $\mathrm{P}$ e de teológico em textos sacerdotais, como parece ser o caso de Nm 5 e Lv 20. Enfim, ele percebe que esses textos refletem a preocupação e centralidade das questões do corpo e da sexualidade para o grupo sacerdotal. Essa preocupação surge do conflito entre a necessidade de procriação - de uma procriação legítima, que gere filhos puros das linhagens patriarcais definidas em Israel - e a afirmação de que o ser humano teria sido criado a "imagem e semelhança de Deus" e que, portanto, deveria esforçar-se para "ser santo como Ele é santo”. Porém, essa questão esbarra na natureza de Deus e na divisão sexualmente definida da humanidade, entre homem e mulher, sendo esse, então, um diferenciador essencial e físico, entre Deus e os seres criados.

É bastante evidente, portanto, o esforço de salvaguardar e proteger a sociedade assentada em clãs patriarcais, em que a identidade individual está intimamente ligada e é mesmo formada a partir de seus ascendentes, e seus ascendentes homens. O indivíduo é reconhecido socialmente não a partir de seu nome próprio, mas do de seu pai. Quando as relações ilícitas e o adultério colocam em dúvida a ordem estabelecida socialmente, o impulso é a exclusão dos envolvidos e de sua descendência impura e indesejada do meio do grupo, como objetos estranhos à integridade social, assim como a ejaculação, a menstruação, as doenças de pele e os defeitos físicos eram vistos como estranhos à integridade do corpo. Nm 5 e Lv 20 também eram considerados leis de proteção nacional pelos sacerdotes de Jerusalém e refletem o medo social por parte de Israel (ou de grupos dentro de Israel) de não cumprir com seu dever de ser o povo santo, escolhido para respeitar a ordem natural que Deus havia estabelecido no mundo desde a criação e de, por esse motivo, tornar-se estéril, tornar sua terra infértil, sofrer o exílio, a morte e o aniquilamento. À mulher, idealmente segundo tais leis, cabia sim fazer parte do sistema social e religioso, mas parte silenciosa e submissa. O desvio, ou a simples aparência dele, porém, poderia tomar-lhe irrevogavelmente esse lugar.

\footnotetext{
${ }^{83}$ PATAI, 1959, p. 82.
} 


\section{Referências}

Bíblia. Traduções:

BÍBLIA com comentários de Rashi. Tradução do Rabino Motel Zajac. São Paulo: Trejger Editores, 1993.

BÍBLIA DE JERUSALÉM. São Paulo: Paulinas, 1985.

BÍBLIA HEBRAICA STUTTGARTENSIA. Stuttgart: Gesamtherstellung Biblia-Druck, Fünfte, verbesserte Auflage, 1997.

BÍBLIA SAGRADA. São Paulo: Ave Maria, 1994.

BÍBLIA TEB: tradução ecumênica. São Paulo: Paulinas e Loyola, 1996.

Dicionários:

BEREZIN, J. Rifka. Dicionário Hebraico-Português. São Paulo: EDUSP, 1995.

BROWN, Francis with the co-operation of DRIVER,S.R. and BRIGGS, C.A. A Hebrew and English Lexicon of the Old Testament. Based on the Lexicon of William Gesenius as translated by Edward Robinson. Oxford: Clarendon Press, 1951.

EVEN SHOSHAN, Avraham. Hamilon Haivri Hamerucaz. Jerusalém: Hemed, Press, 1991.

KIRST, N.; KILPP. N.; SCHWANTES, M.; RAYMANN, A.; ZIMMER, R. Dicionário Hebraico-Português \& Aramaico Português. São Leopoldo: Sinodal: e Petrópolis: Vozes, $11^{\text {a }}$ edição, 2000.

SCHÖKEL, Luis Alonso. Dicionário Bíblico Hebraico-Português. Trad. Ivo Storniolo, José Bortolini. São Paulo: Paulus, 1997.

Bibliografia geral 
BACH, Alice (Ed.). Women in the Hebrew Bible. New York and London: Routledge, 1999.

BIRD, Phyllis A. Missing Persons and Mistaken Identities: Women and Gender in Ancient Israel. Minneapolis: Fortress Press, 1997.

BRENNER, Athalya. A Mulher Israelita: papel social e modelo literário na narrativa bíblica. São Paulo: Paulinas, 2001.

CHOURAQUI, André. Ele Clama (Levítico). Rio de Janeiro: Imago, 1996.

CHOURAQUI, André. No Deserto (Números). Rio de Janeiro: Imago, 1997.

CHWARTS, Suzana. Uma Visão da Esterilidade na Bíblia Hebraica. São Paulo: Humanitas, 2004.

DOUGLAS, Mary. Leviticus as Literature. New York: Oxford University Press, 1999.

EILBERG-SCHWATZ, Howard. The Problem of the Body for the People of the Book. In: BACH, Alice (Ed.). Women in the Hebrew Bible. New York and London: Routledge, 1999.

FUCHS, Esther. The Literary Characterization of Mothers and Sexual Politics in the Hebrew Bible. In: BACH, Alice (Ed.). Women in the Hebrew Bible. New York and London: Routledge, 1999.

FRIEDMAN, Richard Elliott. The Bible with Sources Revealed. San Francisco: HarperSanFrancisco, 2003.

GROSSMAN, Maxine. Reading for Gender in the Damascus Document. Dead Sea Discoveries. A Journal of Current Research on the Dead Sea Scrolls and Related Literature. Volume XI. Leiden; Boston: Brill, pp. 213-239, 2004.

GREENBERG, Moshe. The Anchor Bible: Ezekiel, 1-20 (Volume 22). Garden City: Doubleday \& Company, 1983.

PLAUT, W. Gunther. A Modern Commentary: Numbers. New York: The Union of American Hebrew Congregation, 1979. 
PATAI, Raphael. Sex and Family in the Bible and in the Middle East. Garden City, NY: Doubleday, 1959.

RUETHER, Rosemary Radford. Religion and Sexism: images of woman in the Jewish and Christian traditions. New York: Simon and Schuster, 1974.

SCHIFFMAN, Lawrence. The Pharisees and their Legal Traditions According to the Dead Sea Scrolls. Dead Sea Discoveries. A Journal of Current Research on the Dead Sea Scrolls and Related Literature. Volume VIII. Leiden; Boston: Brill, pp. 262-277, 2001.

SCHWARTZ, Baruch Jacob. הרותבש תינהוכה הקוחב םינויע: השודקה תרות (A Legislação de Santidade: estudos sobre o Código Sacerdotal da Torá). Jerusalem: The Magnes Press and The Hebrew University, 1999 (em hebraico).

SILVA, Clarisse Ferreira da. O Novo Templo e a Aliança Sacerdotal da Comunidade de Qumran. São Paulo: Humanitas, 2013.

ZAJAC, Motel (compilação). Coleção Chumash com comentário de Rashi - Levítico. São Paulo: Trejger Editores, 1993.

ZAJAC, Motel (compilação). Coleção Chumash com comentário de Rashi - Números. São Paulo: Trejger Editores, 1993. 